\title{
Effect of Gamma-Rays on the Growth and Penicillin Production of Penicillium chrysogenum
}

\author{
Mohammed M. Aljeldah' ${ }^{1}$, Hosam El-Sayyad ${ }^{2 *}$, Nasreldin Elhadi $^{3}$ and \\ Ali A. Rabaan ${ }^{4}$
}

${ }^{1}$ Department of Medical Laboratory Technology, College of Applied Medical Sciences, University of Hafr Albaten, Hafr Albaten Saudi Arabia. ${ }^{2}$ Middle Eastern Regional Radioisotope Centre for the Arab Countries, Dokki, Giza, Egypt. (Al-Ghad International College for Applied Medical Sciences Dammam, Kingdom of Saudi Arabia). ${ }^{3}$ Department of Clinical Laboratory Science, College of Applied Medical Sciences, Imam Abdulrahman Bin Faisal University, P.O. Box 2435, 31441 Dammam, Kingdom of Saudi Arabia. ${ }^{4}$ Molecular Diagnostic Laboratory, Johns Hopkins Aramco Healthcare, Dhahran, Saudi Arabia.

\begin{abstract}
This study aimed to investigate the effects of different doses $(25,50,75,100,125,150,200,250,500$, 1000 and $2000 \mathrm{~Gy}$ ) of gamma radiation on spore germination in Penicillium chrysogenum and on the production and efficacy of penicillin in this fungus. A dose of $200 \mathrm{~Gy}$ of gamma radiation increased spore germination by $\mathbf{7 0 . 2 \%}$ after $\mathbf{2 0}$ hours of incubation compared to control cultures. It was also found that penicillin yield increased by $95.2 \%$ at this dose of gamma radiation. The efficacy of penicillin was remarkably enhanced, resulting in a $\mathbf{9 9 . 6 \%}$ reduction in the total count of Staphylococcus aureus treated with penicillin from irradiated $P$. chrysogenum compared with that of $S$. aureus treated with commercially available and purified penicillin from nonirradiated fungi. The results obtained highlighted the potential of this technology for production of penicillin.
\end{abstract}

Keywords: Penicillium chrysogenum, penicillin, gamma radiation.

*Correspondence: helhalby@gc.edu.sa, 0966562983169

(Received: 18 February 2019; accepted: 20 April 2019)

Citation: Mohammed M. Aljeldah, Hosam El-Sayyad, Nasreldin Elhadi and Ali A. Rabaan, Effect of Gamma-Rays on the Growth and Penicillin Production of Penicillium chrysogenum, J Pure Appl Microbiol., 2019; 13(2): 779-788. doi: 10.22207/JPAM.13.2.13

(c) The Author(s) 2019. Open Access. This article is distributed under the terms of the Creative Commons Attribution 4.0 International License which permits unrestricted use, sharing, distribution, and reproduction in any medium, provided you give appropriate credit to the original author(s) and the source, provide a link to the Creative Commons license, and indicate if changes were made. 


\section{INTRODUCTION}

Many microorganisms are used for the production of pharmaceutical agents, including antibiotics. Among them are fungi perform environmental services of human life and provide economic benefits, e.g., Penicillium as a basis for a large pharmaceutical industry of antibiotics ${ }^{1}$. Penicillin is a class of antibiotics that is extracted from Penicillium chrysogenum or Penicillium notatum $^{2}$. However, $P$. chrysogenum gives much more penicillin than $P$. notatum ${ }^{3,4}$ because $P$. chrysogenum carry multiple copies of the penicillin biosynthesis gene cluster ${ }^{5}$. Therefore, $P$. chrysogenum is still the main fungal species used for the production of penicillin. Penicillin is more effective against gram-positive bacteria than gramnegative bacteria by disrupting the synthesis of the peptidoglycan polymerase enzyme ${ }^{6}$.

The production rate of penicillin from fungal cultures is relatively low under normal cultivation conditions. Nevertheless, the fungal growth and penicillin production rates increase when certain controlled substances are used in growth media under suitable physical conditions ${ }^{7}$. Tugay et $a .^{8}$ reported that the low doses of gamma radiation (200-400 Gy) stimulated spore germination and hyphal growth. Few reports are available on mutagenesis in fungi by gamma radiation $^{9-11}$. Additionally, Thykaer and Nielsen ${ }^{12}$ and Tawfik, et al. ${ }^{13}$ revealed that irradiation of the fungus may considerably improve penicillin production due to high sporulation and morphology variation of mutant strains of Penicillium chrysogenum ${ }^{14}$. Recently, UV irradiation was used to increase the production of penicillin in a mutant strain of $P$. chrysogenum ${ }^{15-16}$.

Basically, this study aimed to investigate the efficiency of gamma radiation in improving fungal growth and producing a natural type of cost-effective, sustainable penicillin from mutant derived strain of $P$. chrysogenum.

\section{MATERIALS AND METHODS Isolation of Penicillium chrysogenum from spoiled fruit}

Since $P$. chrysogenum is a common fungus found in spoiled food and moist soil, a stock culture was isolated from spoiled orange fruits. The general plating method was employed to isolate the organism and plate it onto Sabouraud Dextrose agar media (peptone, preferably mycological, $1 \%$, dextrose $4 \%$, agar $1.5 \%$, pH 5.6). Several replicas of pure cultures were extracted to expose the cultures to different durations and doses of gamma radiation.

\section{Identification of $P$. chrysogenum}

One $\mu l$ (per spot) of fungal spore suspensions isolated from spoiled orange fruits were inoculating onto sterile Sabouraud Dextrose agar media and then incubated at the standard temperature of $25^{\circ} \mathrm{C}$ for 7 days.

After 7 days, The fungal cultures were identified on the basis of macroscopic (colony morphology, color, texture, shape, diameter, degree of sporulation, colour of mycelia, the presence and colours of soluble pigments and exudates, colony reverse colours, and degree of growth) characteristics ${ }^{17}$ and microscopic (mycelium septations, presence of specific reproductive structures, shape and structure of conidia, and presence of sterile mycelium) characteristics $^{18-19}$.

\section{Maintenance of the microorganism}

Experimental cultures were descendants of the pure organism and were maintained on agar slants of modified Dox's medium.

\section{Source of gamma irradiation}

The spores of $P$. chrysogenum were exposed to gamma rays from a Cobalt-60 gamma cell source located at the National Center for Radiation Research and Technology - Atomic Energy Authority, Nasr City, Cairo with a dose rate of $13.3 \mathrm{~Gy} / \mathrm{min}$ for the experimental time.

\section{Spore preparation and irradiation}

Sufficient quantities of spores were extracted by performing a spore print from $P$. chrysogenum cultures. This was accomplished by placing a spatula down on sterile petri dishes. The spores were then scraped as the colony was flooded with sterile saline $(0.85 \% \mathrm{NaCl})$ and were diluted into a suspension of $5 \times 10^{6}$ spore/ $\mathrm{ml}$ in a sterile beaker. The spore suspension was then distributed into sterile Eppendorf tubes $(1.5 \mathrm{ml}$ each) and was irradiated with gamma rays separately at doses of $25,50,75,100,125$, 150, 200, 250, 500, 1000 and $2000 \mathrm{~Gy}$. Three Eppendorf tubes were used as controls, without being irradiated ${ }^{20-21}$. Spore germination and mycelial growth were described as the following and compared for each dose. 


\section{Determination of spore germination}

Spore germination percentages were determined by inoculating separately $200 \mu \mathrm{l}$ of irradiated and nonirradiated (control) fungal spore suspensions on sterile agar plates containing $2 \%$ water-agar at $27^{\circ} \mathrm{C}$. The resulting cultures were then examined under a microscope at different intervals $(4,8,12,16,20$ and 24 hours) post inoculation $^{22}$. The spore germination percentage was calculated as follows:

Spore germination $=\frac{\text { Total count of germinated spores }}{\text { Total count of spores }} 100$ percent

\section{Determination of mycelial growth}

The fungal mycelial growth for each culture was determined by inoculation of $1 \mathrm{ml}$ of irradiated and nonirradiated fungal spore suspensions into sterile $250 \mathrm{ml}$ conical flasks, each containing $100 \mathrm{ml}$ of Sabouraud dextrose liquid media, followed by incubation at $27^{\circ} \mathrm{C}$ for 15 days.

Following this period of incubation, flasks were filtrated, and the resulting mycelia were dried at $50^{\circ} \mathrm{C}^{23}$.

\section{Extraction of penicillin}

The liquid-liquid method was executed for the extraction of penicillin from different shaking flask cultivation systems ${ }^{24}$.

Penicillin recovery from penicillin-rich aqueous broth (100 $\mathrm{ml}$ ) was performed by liquidliquid extraction (solvent extraction). Penicillin was extracted from an aqueous phase using acetyl acetate as the solvent. Finally, the extraction was transferred from acetyl acetate into a $2 \%$ sodium acetate solution.

\section{Using TLC for the detection of penicillin G.}

Thin layer chromatography (TLC) was used to detect the presence of penicillin isolated from the first and second generations of irradiated and non-irradiated $P$. chrysogenum cultures by acetyl acetate. The obtained samples and standards of penicillin were then developed with benzene: ethylacetate: acetic acid (40:40:20) as the solvent ${ }^{25}$ on a TLC plate. The plate was sprayed with ninhydrin reagent ${ }^{26}$ and heated at $110^{\circ} \mathrm{C}$ for $5 \mathrm{~min}$.

\section{HPLC analysis of penicillin}

HPLC analysis of penicillin was conducted in the Institute for Research and Medical Consultations (IRMAC)-Cell Signaling
Lab, Department of Genetic Research - Imam Abulrahman Bin Faisal University, Saudi Arabia, with a UV detector set at $220 \mathrm{~nm}$ and using a $\mathrm{C}-18$ column. The mobile phase consisted of $[\mathrm{A}]$ $10 \mathrm{mM}$ ammonium acetate (pH 4.5 acetic acid): [B] acetonitrile, (75:25, A:B) at a flow rate of 1 $\mathrm{mL} / \mathrm{min}^{27}$. The standards used for comparison were from the commercially available penicillin injection.

\section{Characterization of purified penicillin Microorganism}

Staphylococcus aureus (S. aureus, obtained from King Fahad Hospital, Imam Abdulrahman Bin Faisal University, Saudi Arabia) was used for testing the antibacterial activity of extracted penicillin.

\section{Inoculation and growth conditions}

Two milliliters of penicillin extracted from each fungal culture was placed in sterile test tubes with fresh cultures of $S$. aureus at an initial concentration of $1-3 \times 10^{5} \mathrm{CFU} / \mathrm{ml}$, and the tubes were then incubated at $37^{\circ} \mathrm{C}$. Viable counts were performed on overnight incubated bacterial cultures. Viable populations were recorded as colony-forming units per milliliter (CFU/ ml) after incubation at $37^{\circ} \mathrm{C}$ overnight on blood agar plates.

\section{Statistical analysis}

All data represented herein are the average of triplicates for each experimental procedure and were analyzed using the Statistical Package for the Social Sciences (SPSS), Version 20 software ${ }^{28}$ using one-way analysis of variance (ANOVA). Significant differences were calculated $(P<0.05)$ using least significant differences (LSD).

\section{RESULTS}

Isolation and Identification of $\boldsymbol{P}$. chrysogenum

The data obtained from examinations confirmed that $P$. chrysogenum was the isolated fungus (Fig. 1).

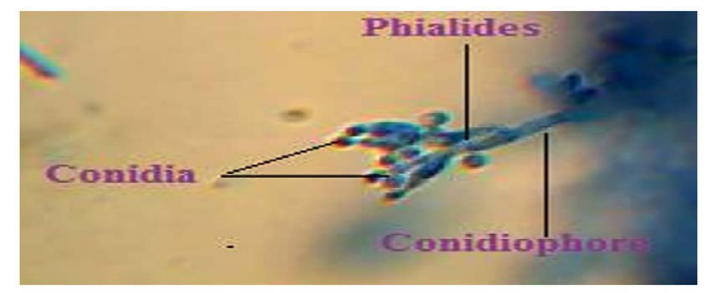

Fig. 1. A microscopic picture of Penicillium chrysogenum 
Influence of different doses of gamma rays on the germination of $\boldsymbol{P}$. chrysogenum spores

The effect of gamma irradiation on spore germination in $P$. chrysogenum was investigated. Table (1) indicates that during the first 4 hours of incubation, there was no sign of germination of irradiated and nonirradiated (control) spores in $P$. chrysogenum. After a period of 4 hours, the table shows that the spore germination rate increased with time in all cultures of both irradiated and control spores. Following twenty-four hours of incubation, high germination percentages of nonirradiated spores (56.8\%)were observed in $P$. chrysogenum. At low experimental doses of gammarays $(25,50,75,100,125,150$ and 200 Gy), a stimulatory effect of spore germination was noticed, and the highest percentage of spore germination (70.2\%) was recorded at $200 \mathrm{~Gy}$ after 24 hours of incubation (Fig. 2). At radiation doses higher than $200 \mathrm{~Gy}$, the percentage of spore germination significantly decreased, reaching $39.1 \%$ at a dose of 2000 Gy compared to the controls (Table 1).

Table 1. Spore germination percentages of Penicillium chrysogenum after irradiation with gamma rays

\begin{tabular}{lcccccc}
\hline Dose(Gy) & \multicolumn{5}{c}{ Spore germination \% } \\
\cline { 2 - 7 } & $4 \mathrm{~h}$ & $8 \mathrm{~h}$ & $12 \mathrm{~h}$ & $16 \mathrm{~h}$ & $20 \mathrm{~h}$ & $24 \mathrm{~h}$ \\
\hline Control** & 0 & $29.1 \pm 1.9$ & $37.9 \pm 2.1$ & $43.2 \pm 1.7$ & $49.5 \pm 1.5$ & $56.8 \pm 1.1$ \\
25 & 0 & $35 \pm 3.1$ & $43 \pm 2.5$ & $48 \pm 2.6$ & $51 \pm 1.2$ & $57.7 \pm 2.0$ \\
50 & 0 & $33 \pm 1.5$ & $40 \pm 1.0$ & $47 \pm 1.7$ & $50 \pm 0.9$ & $58.2 \pm 1.0$ \\
75 & 0 & $34 \pm 2.5$ & $45 \pm 2.0^{*}$ & $48 \pm 2.7$ & $51 \pm 1.3$ & $59.0 \pm 2.0$ \\
100 & 0 & $32 \pm 1.0$ & $40 \pm 1.0$ & $45 \pm 0.8$ & $52 \pm 1.8$ & $58.0 \pm 1.1$ \\
125 & 0 & $39 \pm 1.5^{*}$ & $46 \pm 1.9^{*}$ & $47 \pm 1.8$ & $53.2 \pm 2.0$ & $57.9 \pm 1.0$ \\
150 & 0 & $38 \pm 2.0^{*}$ & $45 \pm 1.3^{*}$ & $46 \pm 1.1$ & $52.6 \pm 1.9$ & $57.1 \pm 0.9$ \\
200 & 0 & $41 \pm 1.0^{*}$ & $49 \pm 2.0^{*}$ & $54 \pm 2.0^{*}$ & $61 \pm 1.9^{*}$ & $70.2 \pm 1.0^{*}$ \\
250 & 0 & $31 \pm 1.5$ & $39 \pm 1.1$ & $44 \pm 1.1$ & $49 \pm 0.3$ & $53.5 \pm 2.0$ \\
500 & 0 & $28 \pm 2.2$ & $30 \pm 2.8^{*}$ & $37 \pm 1.0^{*}$ & $42 \pm 1.0^{*}$ & $49.5 \pm 1.3^{*}$ \\
1000 & 0 & $22 \pm 3.0^{*}$ & $27 \pm 2.0^{*}$ & $28 \pm 1.3^{*}$ & $34 \pm 2.1^{*}$ & $40.3 \pm 1.9^{*}$ \\
2000 & 0 & $20 \pm 2.0^{*}$ & $25 \pm 1.0^{*}$ & $27 \pm 1.4^{*}$ & $33 \pm 2.2^{*}$ & $39.1 \pm 2.0^{*}$ \\
\hline
\end{tabular}

*Significant differences from the control $(\mathrm{P}<0.05)$.;

** Control (nonirradiated spores).

Mycelium growth of $P$. chrysogenum affected by irradiation with gamma rays

The effect of gamma ray exposure doses on mycelial growth was investigated. Table (2) represents the average mycelial dry weights of $P$. chrysogenum after irradiation by gamma rays. The results in this table reveal that the doses of 100 , 125, 150 and 200 Gy significantly increased the mycelial dry weight.

The highest yields were observed at a dose of $200 \mathrm{~Gy}(1.2 \mathrm{~g} / 100 \mathrm{ml})$ compared to those in the controls $(0.57 \mathrm{~g} / 100 \mathrm{ml})$; however, with higher gamma radiation doses, the growth significantly decreased, reaching a minimum value of 0.02 $\mathrm{g} / 100 \mathrm{ml}$ dry weight at a dose of $2000 \mathrm{~Gy}$.

TLC analysis of purified penicillin

In this study, the irradiated and nonirradiated $P$. chrysogenum grew well in
Table 2. Influence of gamma rays on dry weight (g/100 $\mathrm{ml}$ ) of $P$. chrysogenum.

\begin{tabular}{lc}
\hline $\begin{array}{l}\text { Doses } \\
\text { (Gy) }\end{array}$ & $\begin{array}{c}\text { Mean Dry weight } \\
\text { (g/100 ml) }\end{array}$ \\
\hline Control** $^{*}$ & $0.57 \pm 0.02$ \\
25 & $0.52 \pm 0.02$ \\
50 & $0.54 \pm 0.03$ \\
75 & $0.53 \pm 0.03$ \\
100 & $0.61 \pm 0.05^{*}$ \\
125 & $0.85 \pm 0.04^{*}$ \\
150 & $0.88 \pm 0.02^{*}$ \\
200 & $1.20 \pm 0.05^{*}$ \\
250 & $0.43 \pm 0.07$ \\
500 & $0.03 \pm 0.02^{*}$ \\
1000 & $0.03 \pm 0.01^{*}$ \\
2000 & $0.02 \pm 0.02^{*}$ \\
\hline
\end{tabular}

*Significant differences from the control $(\mathrm{P}<0.05)$.

** Control (nonirradiated spores). 

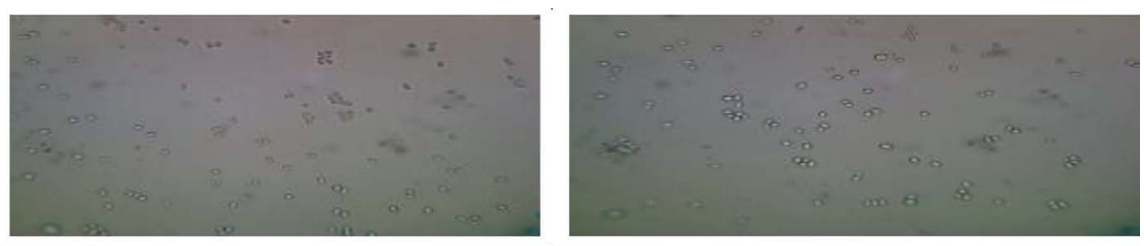

Effect of gamma radiation on the germination of spores after four hours

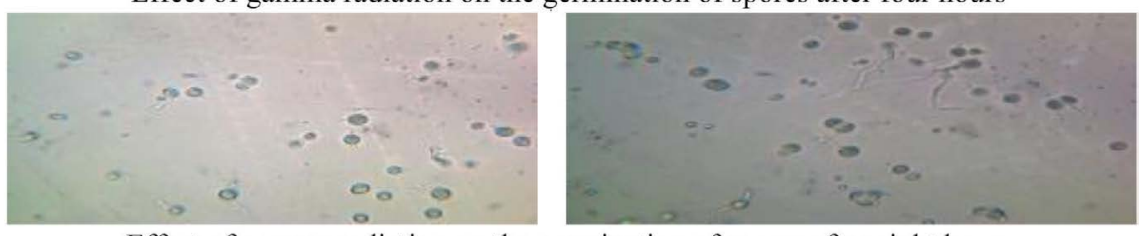

Effect of gamma radiation on the germination of spores after eight hours

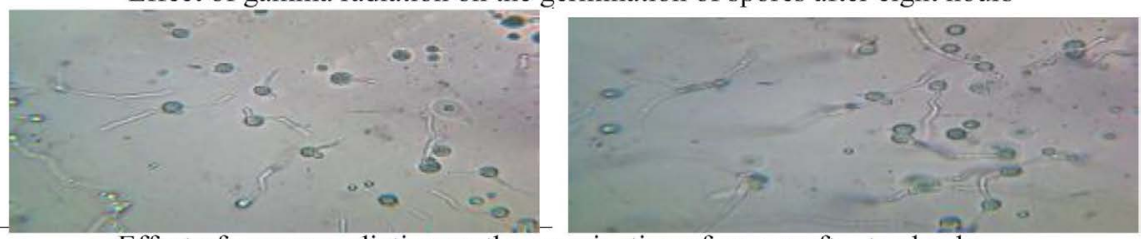

Effect of gamma radiation on the germination of spores after twelve hours

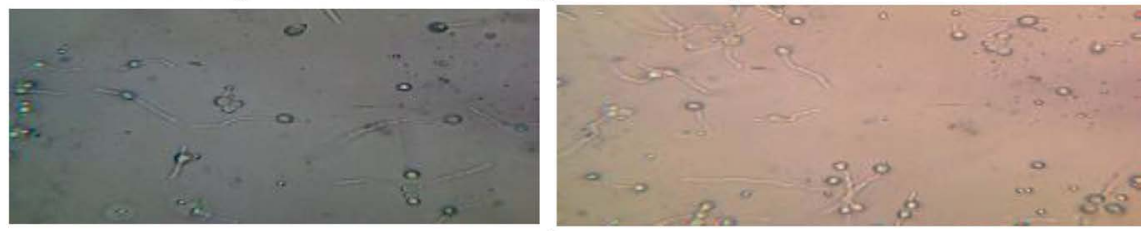

Effect of gamma radiation on the germination of spores after sixteen hours

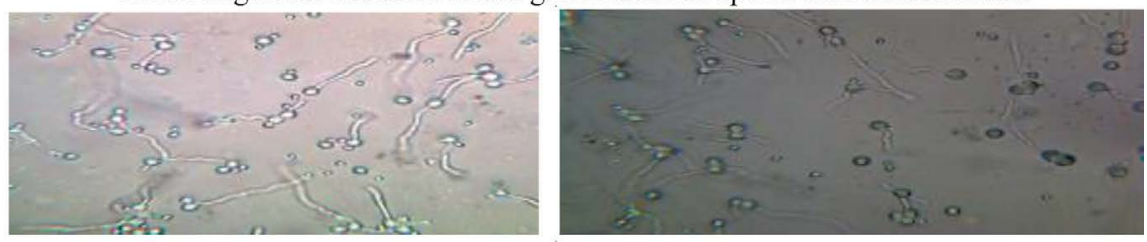

Effect of gamma radiation on the germination of spores after twenty hours
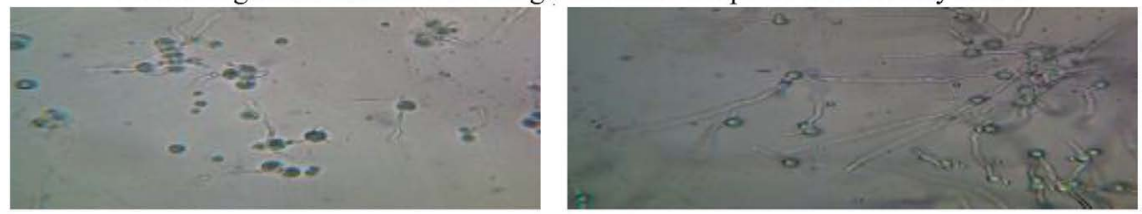

Effect of gamma radiation on the germination of spores after twenty four hours

Fig. 2. Germination of Penicillium chrysogenum spores either gamma radiated at a dose of 200 Gy or nonirradiated

Sabouraud Dextrose liquid media and produced substances inhibiting the growth of bacteria. The anti-critical composition of penicillin in this medium was determined using the TLC method and was compared with that of standard penicillin G (Fig. 1). The purified penicillin from irradiated and nonirradiated samples was confirmed using analytical TLC. The samples showed pale spots at all gamma irradiation doses except at $200 \mathrm{~Gy}$, which showed clear colored bands. However, there were no bands detected at doses of 1000 and 2000 Gy after spraying with ninhydrin (Fig. 3).

HPLC analysis of purified penicillin

Comparisons of spore germination, mycelial growth, and antibacterial activity of penicillin were carried out to evaluate the most effective dose of gamma irradiation. According to the data presented, the dose of 200 Gy was found to be the most effective and thus was selected for the HPLC analysis. Table (3) shows penicillin 


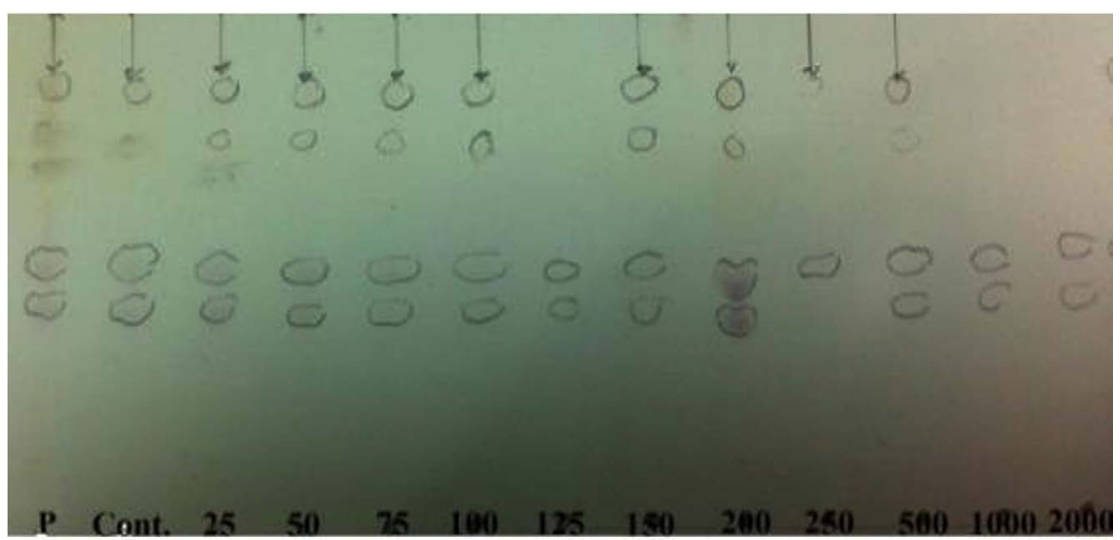

Doses (Gy)

Fig. 3. Analytical TLC image of various doses of gamma ray samples of penicillin extracted from P.chrysogenum

Table 3. Production of penicillin by wild-type and mutant strains of $P$. chrysogenum

\begin{tabular}{|c|c|c|}
\hline $\begin{array}{l}\text { Doses } \\
\text { (Gy) }\end{array}$ & $\begin{array}{l}\text { Concentration } \\
(\mathrm{mg} / \mathrm{ml})\end{array}$ & Percentage \\
\hline Control** & $2.54 \pm 0.61$ & 0.0 \\
\hline $200 \mathrm{~Gy}$ & $4.96 \pm 0.75^{*}$ & 95.2 \\
\hline
\end{tabular}

*Significant differences from the control $(\mathrm{P}<0.05)$.

** Control (nonirradiated spores).

production by wild-type and selective mutant strains of $P$. chrysogenum. The mutant strain of $P$. chrysogenum irradiated with $200 \mathrm{~Gy}$ showed the highest yield of penicillin $(4.96 \mathrm{mg} / \mathrm{ml})$ compared with the wild-type strain $(2.54 \mathrm{mg} / \mathrm{ml})$.

\section{Characterization of purified penicillin}

Table (4 and 5) represents the antimicrobial activity against $S$. aureus by commercial and purified penicillin from $P$. chrysogenum after being irradiated by gamma rays. The purified penicillin from irradiated and nonirradiated samples gave better results than commercial penicillin. The purified penicillin from $P$. chrysogenum irradiated with $200 \mathrm{~Gy}$ was more effective than the other samples tested (table 5). The total count of $S$. aureus treated with penicillin from the samples irradiated with $200 \mathrm{~Gy}$ was markedly reduced to $0.2 \times 10^{5} \mathrm{CFUs} / \mathrm{ml}$, which is a reduction rate of $99.6 \%$ (Fig. 4), compared to that of the samples

Table 4. Effect of commercial penicillin on colony counts (CFUs/ml) of S. aureus

\begin{tabular}{lcc}
\hline Type & $\begin{array}{c}\text { Colony Count } \\
\times 10^{5} \text { CFUs/ml }\end{array}$ & $\begin{array}{c}\text { Reduction } \\
\%\end{array}$ \\
\hline Blank** & 100 & 0 \\
Commercial & $4.0 \pm 0.6$ & 96 \\
Penicillin*** & &
\end{tabular}

**Media without penicillin.

$* * *$ Media with commercial penicillin.

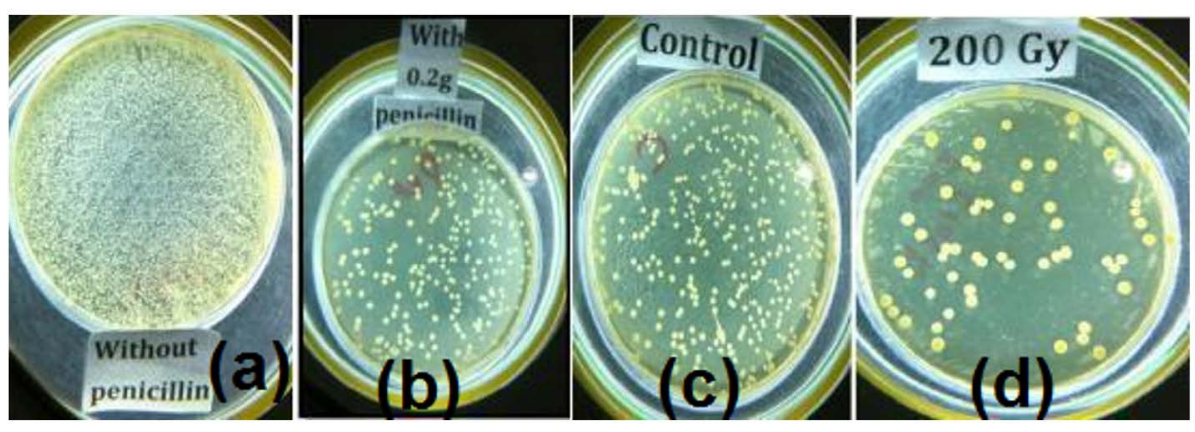

Fig. 4. Characterization of commercial and purified penicillin from P. chrysogenum on S. aureus. (a) Colony count without penicillin. (b) Colony count with commercial penicillin. (c) Colony count with purified penicillin from nonirradiated $P$. chrysogenum .(d) Colony count with purified penicillin from irradiated $P$. chrysogenum. 
treated with commercial penicillin (Table 4) and purified penicillin from nonirradiated fungi (Table 5).

Table 5. Effect of purified penicillin on colony counts (CFUs/ml) of S. aureus

\begin{tabular}{lcc}
\hline Doses (Gy) & $\begin{array}{c}\text { Colony Count } \\
\text { x } 105 \text { CFUs/ml }\end{array}$ & $\begin{array}{c}\text { Reduction } \\
\%\end{array}$ \\
\hline Blank** & 100 & 0 \\
Control**** & $5.5 \pm 0.5$ & 94.5 \\
25 & $14.0 \pm 2.0^{*}$ & 86 \\
50 & $24.0 \pm 2.1^{*}$ & 76 \\
75 & $11.0 \pm 3.0^{*}$ & 89 \\
100 & $10.0 \pm 1.0^{*}$ & 90 \\
125 & $26.0 \pm 5.0^{*}$ & 74 \\
150 & $17.0 \pm 1.9^{*}$ & 83 \\
200 & $0.20 \pm 0.1^{*}$ & 99.8 \\
250 & $31.0 \pm 4.0^{*}$ & 69 \\
500 & $21.0 \pm 3.0^{*}$ & 79 \\
1000 & $34.0 \pm 4.9^{*}$ & 66 \\
2000 & $35.0 \pm 3.8^{*}$ & 65 \\
\hline
\end{tabular}

*Significant differences from the control $(P<0.05)$.

**Media without penicillin.

*** Media with commercial penicillin.

**** Media with extracted penicillin from nonirradiated fungi.

\section{DISCUSSION}

One of the major problems that researchers face is low penicillin titers produced by the original $P$. notatum strain and the increasing demand of antibiotics ${ }^{29}$.

In this context, the objectives of our study were to investigate the effects of gamma irradiation on the production of penicillin by $P$. chrysogenum.

In the current study, P. chrysogenum spores were irradiated with different doses of gamma radiation, and the potential of $P$. chrysogenum to grow and produce penicillin was analyzed. In general, at lower radiation doses, there was an increase in the spore germination and mycelial growth of $P$. chrysogenum but a gradual decrease at higher radiation doses.

Our results revealed that there was no effect on the germination of irradiated and nonirradiated spores during the first four hours of incubation. This finding is probably attributed to the swelling of spores, which occurs before effective germination ${ }^{30}$.
The viability of fungi after irradiation also revealed that low doses of gamma irradiation significantly increased the viability of fungal spores. These results were in agreement with those of ElAbyad and Ismail ${ }^{31}$, which illustrated that the spore germination and mycelial growth of some fungi were stimulated by low dose of gamma irradiation (50 Gy). These results are also in agreement with those of Adams et al. ${ }^{32}$, who observed that the mycelial growth of Penicillium expansum and Penicillium patulum were stimulated by low doses of gamma rays (1.5 KGy). Some other studies ${ }^{33-34}$ support the findings of this study, who reported that the simulative biological effects produced by low-dose irradiation of organisms have been studied extensively because low-dose irradiation brings about effects that differ from those produced by high-dose irradiation.

In our study, it was found that the high dose of gamma irradiation, $2000 \mathrm{~Gy}$, inhibited the growth of $P$. chrysogenum. these may be due to that the gamma rays destroy the DNA structure of cells and that cells cannot continue to function, while incomplete inhibition may result from a small injuries to cells ${ }^{34}$. These results agreed with those of previous investigations that showed that exposure to high doses of radiation resulted in the complete inhibition of spore germination ${ }^{35}$. Those previous studies also showed that $A$. ochraceus spore germination was completely inhibited at 600 Gy, while a noticeable activation was recorded at lower doses. The irradiation of fungal isolates with 400 Gy showed no observable effects on spore germination ${ }^{36}$.

This finding could be explained by proposing that higher doses of irradiation may initiate a shock to the spores, which requires more time for recovery, or it may be attributed to the possibility of toxic substance production ${ }^{37}$.

The purpose of the present investigation was to enhance the production of penicillin by subjecting the wild-type strain of $P$. chrysogenum to gamma irradiation.

Among all the mutants tested, the mutant of the P.chrysogenum strain treated at 200 Gy showed the highest penicillin production compared with the parent strain.

The increase in penicillin production from the irradiated strain may be a consequence 
of metabolic reorganizations ${ }^{38}$. However, gamma radiation may induce the enzymes that are involved in the last step of penicillin biosynthesis, namely, acyltransferase, phenylacetyl-CoA ligase and isopenicillin $\mathrm{N}$ acyltransferase ${ }^{38-39}$. This may also be explained by the modifications of a microsomal cytochrome P450 monooxygenase that leads to the over production of penicillin ${ }^{40}$ or the amplification of the genomic region that includes the three penicillin biosynthesis genes ${ }^{41-43}$.

These data agree with previously reported results of other studies ${ }^{15-16}$ that revealed that the strain of $P$. chrysogenum irradiated with ultraviolet rays exhibited increased penicillin production over the parent strain.

In our study, the extracted penicillin from irradiated $P$. chrysogenum showed significant antimicrobial activity against the clinical isolate of $S$. aureus compared to the extracted penicillin from the parent strain and commercial penicillin. This may be due to the overproduction of penicillin and the ability of penicillin to reach intracellular spaces and denature the bacterial cell wall.

\section{CONCLUSION}

These results demonstrate that gamma radiation is a successful method for improving the production of penicillin. The ability of gamma radiation to change the structural characteristics and bioactivities of penicillin is not only cost effective and sustainable but also an environmentally friendly approach to natural penicillin production.

\section{CONSENT FOR PUBLICATION}

We (all co-authors, who signed this letter) certify that we have participated sufficiently in the intellectual content, conception and design of this work or the analysis and interpretation of the data (when applicable), as well as the writing of the manuscript, to take public responsibility for it and have agreed to have our name listed as a contributor. We believe the manuscript represents valid work. Neither this manuscript nor one with substantially similar content under our authorship has been published or is being considered for publication elsewhere, except as described in the covering letter. We certify that all the data collected during the study is presented in this manuscript and no data from the study has been or will be published separately. We attest that, if requested by the editors, we will provide the data/ information or will cooperate fully in obtaining and providing the data/information on which the manuscript is based, for examination by the editors or their assignees.

We give the rights to the corresponding author to make necessary changes as per the request of the journal, do the rest of the correspondence on our behalf and he/she will act as the guarantor for the manuscript on our behalf. Yours sincerely,

Author's Name

1 Mohammed M. Aljeldah: Main author

2 HosamEldin El-Sayyad: Corresponding author 3 NasreldinElhadi: Co-author

4 Ali A. Rabaan: Co-author

\section{ACKNOWLEDGEMENTS}

The authors express their gratitude to Al-Ghad International Colleges of Applied Medical Sciences in Dammam, Saudi Arabia for providing the necessary facilities and the use of various laboratories and We are grateful also to the Deanship of Scientific Research Imam Abdulrahman bin Faisal University for supporting our research (grant No. 2014130).

\section{CONFLICTS OF INTEREST}

All authors declares that there is no conflict of interest.

\section{FUNDING}

This work was supported by the Deanship of Scientific Research at the Imam Abdulrahman Bin Faisal University, grant No. 2014130.

\section{DATA AVAILABILITY}

All datasets generated or analyzed during this study are included in the manuscript.

\section{ETHICS STATEMENT}

This article does not contain any studies with human participants or animals performed by any of the authors.

\section{REFERENCES}

1. Diana W.F. Soil biodiversity: its importance to ecosystem processes. Fort Collins. Colorado State 
University, 1994.

2. Laich F., Fierro F., Martan J.F. Production of Penicillin by Fungi Growing on Food Products: Identification of a Complete Penicillin Gene Cluster in Penicillium griseofulvum and a Truncated Cluster in Penicillium verrucosum. Appl. Environ. Microbiol., 2002; 68(3): 1211-1219 DOI: 10.1128/AEM.68.3.1211-1219.2002

3. Guzmבn-Chבvez F., Zwahlen R.D., Bovenberg R.A.L., Driessen A.J.M. Engineering of the Filamentous Fungus Penicillium chrysogenum as Cell Factory for Natural Products. Frontiers in Microbiology, 2018; 9: 1-25. https://doi.org/10. 3389/fmicb.2018.02768.

4. Sivakumari V.1, Dhinakaran J., Rajendran A. Screening and productivity of penicillin antibiotic from Penicillium sp. Journal of Environmental Science and Engineering, 2009; 51(4): 247-8.

5. Ziemons S., Koutsantas K., Becker K., Dahlmann T., Kck U. Penicillin production in industrial strain Penicillium chrysogenum P2niaD18 is not dependent on the copy number of biosynthesis genes. BMC Biotechnology, 2017; 17: 16. doi: 10.1186/s12896-017-0335-8.

6. Demain A.L. The mechanism of penicillin biosynthesis. Adv. Appl. Microbiol, 1959; 1: 23-47.

7. Lara C., Mateos F.R., Vבzquez G., Sבnchez S. Induction of penicillin biosynthesis by I-glutamate in Penicillium chrysogenum. Biochem. Biophys. Res. Commun., 1982; 105: 172-178.

8. Tugay T., Zhdanova N.N., Zheltonozhsky V., Sadovnikov L., Dighton J. The influence of ionizing radiation on spore germination and emergent hyphal growth response reactions of microfungi. Mycologia., 2006; 98(4): 521-527.

9. Awan M.S., Tabbasam N., Ayub N., Babar M.E., Rahman M., Shahid Mahboob Rana, Rajoka M.I. Gamma radiation induced mutagenesis in Aspergillus niger to enhance its microbial fermentation activity for industrial enzyme production. Mol. Biol. Rep., 2011; 38: 1367-1374 DOI 10.1007/s11033-010-0239-3

10. Haq I., Khurshaid S., Ali S., Ashraf H., Qadeer M.A., Rajoka M.I Mutation of Aspergillus niger for hyperproduction of citric acid from black strap molasses. World J. Microbial Biotechnol., 2001; 17: 35-37.

11. Rincon A.M., Codon A.C., Castrejon F., Benitez T. Improved properties of baker's yeast mutant resistant to 2-deoxy-D-glucose. Appl. Environ. Microbiol., 2001; 67: 4279-4285

12. Thykaer J., Nielsen J. Metabolic engineering of betalactam production. Journal of Metabolic Engineering, 2003; 5: 56-69. https://doi.org/10.1016/S10967176(03)00003-X

13. Tawfik Z.S., Ashour M.S., \& Shihab A. Penicillin production by mutant strains of penicillium chrysogenum. Egyptian Journal of Radiation Sciences and Applications, 1986; 3(2): 159-165.

14. Veerapagu M., Jeya K.R., Ponmurugan K. Mutational effect of Penicillium chrysogenum on Antibiotic Production. Advanced Biotech., 2008; p 16-19.

15. Onyegeme-Okerenta B.M., Okochi V.I., Chinedu S. N. Penicillin Production by Penicillium chrysogenum PCL 501: Effect of UV Induced Mutation. Internet J. Microbiol., 2013; 12: 1-7.http://ispub.com/IJMB/12/1.

16. Karunakar K., Veeragani N., Gundlapally J., Gummadi
T. Comparative estimation of Penicillin production by wild and UV irradiated mutant strains of Penicilliumchrysogenum. Triple Helix (Heidelb), 2012; 1: 134-137. http://helix. dnares.in/category/2012/ page/3/

17. Ramnrez C. Elsevier Biomedical Press; Amsterdam: Manual and atlas of the Penicillia, 1982.

18. Pitt J.I. Academic Press Inc; London: The genus Penicillium and its teleomorphic states Eupenicillium and Talaromyces, 1979.

19. Visagie C.M., Houbraken J., Frisvad J.C., et al. Identification and nomenclature of the genus Penicillium. Stud. Mycol., 2014; 78: 343-371. doi: [10.1016/j.simyco.2014.09.001].

20. Cuero R.G., Smith J.E., Lacey J. The influence of gamma irradiation and sodium hypochloride sterilization on maize seed micro flora and germination. Food Microbiology, 1986; 3: $107-113$.

21. Gupta P.C., Bajpai V., Mishra V., Saxena R.K., Singh $S$. Effect of gamma irradiation on microbial load, aflatoxins and phytochemicals present in Trigonella foenum-graecum. World Journal of Microbiology and Biotechnology, 2009; 25: $2267-2271$

22. Mohammedi Z., Fungitoxic F.A. Effect of natural extracts on mycelial growth, spore germination and aflatoxin B1 production of Aspergillus flavus. Australian Journal of Crop Science(AJCS), 2013;7(3):293-298.

23. Boumaaza B., Benkhelifa M., Belkhoudja M. Effects of Two Salts Compounds on Mycelial Growth, Sporulation, and Spore Germination of Six Isolates of Botrytis cinerea in the Western North of Algeria, International Journal of Microbiology, 2015; 2015: 1-8, http://dx.doi.org/10.1155/2015/572626.

25. Vandamme E.J., Voets J.P. Separation and detection of degradation products of penicillins and cephalosporins by means of thin-layer chromatography. J. Chromatogr., 1972; 71(1): 141-148. https://doi.org/10.1016/S00219673 (01)85698-3.

26. Gabriel H., Brigitte S., Hanja K., Aura R., Eleonora M., Arpad $\mathrm{G}$. Thin layer chromatographic analysis of betalactam antibiotics. Adv. Pharm. Bull., 2013; 3: 367-371.

27. Asnaashari M., Ghanbary M.A.T, Tazick Z. Optimization of penicillin $\mathrm{G}$ production by Penicillium chrysogenum. Annals of Biological Research, 2012; 3(12):5434-5440.

28. Snedecor G.W. and Cochran W.G. Statistical Methods, Seventh Edition, Ames: lowa State University Press; 1980.

29. Ozcengiz A., Demain A.L. Recent advances in the biosynthesis of penicillins, cephalosporins and clavams and its regulation. Biotechnology Advances, 2013; 31(2) : 287-311.https://doi.org/10.1016/j. biotechadv.2012.12.001

30. Mesquita N., Ortugal A., Pioar G., et al. Flow cytometry as a tool to assess the effects of gamma radiation on the viability, growth and metabolic activity of fungal spores. Int. Biodeterior Biodegradation, 2013; 84: 250257. https://doi.org/10.1016/j.ibiod. 2012.05.008.

31. El-Abyad M.S., Ismail I.K. Germination of non-irradiated and gamma-irradiated fungal spores on water agar and natural soil. Zentralbl Bacteriol Naturisms, 1979; 134(8): 681-7.

32. Adams K.B., Wu M.T., Salunkhe D.K. Effects of 
gamma radiation on growth and patulin production of Penicillium expansum and Penicillium patulim. Environ. Exp. Bot., 1976; 16: 189-193.https://doi. org/10.1016/0098-8472(76)90012-5.

33. Luckey T.D. Physiological benefits from low levels of ionizing radiation. Health Phys., 1982; 43: 771-789.

34. Macklis R.M., Beresford B. Radiation Hormesis. J. Nucl. Med., 1991 ; 32: 350-359.

34. Smith J.C., Pillai S. Irradiation and food safety. Food Technol., 2004; 58: 48-54. Direct Link.

35. Applegate K.L., Chipley J.R. Production of ochratoxin A by Aspergillusochraceus NRRL-3174 before and after exposures to 60Co irradiation. Appl. Environ. Microbiol., 1976; 31: 349-353.

36. Schindler A.F., Abadie A.N., Simpson R.E. Enhanced aflatoxin production by Aspergillusflavus and Aspergillusparasiticus after gamma irradiation of the spore inoculum. J. Food Prot., 1980; 43: 7-9. https:// doi.org/10.4315/0362-028X-43.1.7.

37. Pouget J.P., Mather S.J. General aspects of the cellular response to low- and high- LET radiation. Eur. J. Nucl. Med., 2001; 28: 541-561.

38. Martan J.F., Ullan R.V., Garcua-Estrada C. Regulation and compartmentalization of $\lambda$-lactam biosynthesis. Microb. Biotechnol. 2010; 3: 285-299.

39. M ller W.H., van der Krift T.P., Krouwer A.J., et al. Localization of the pathway of the penicillin biosynthesis in Penicilliumchrysogenum. EMBO J., 1991; 10: 489-495.

40. Rodraguez-Sבiz M., Barredo J.L., Moreno M.A., Fern בndez-Caoๆn J.M., Peoalva M.A., Doez B. Reduced function of a phenylacetate-oxidizing cytochrome P450 caused strong genetic improvement in early phylogeny of penicillin-producing strains. J. Bacteriol., 2001; 183: 5465-5471.

41. Fierro F., Barredo J.L., Doez B., Gutierrez S., Fernבndez F.J., Marton J.F. The penicillin gene cluster is amplified in tandem repeats linked by conserved hexanucleotide sequences. Proc. Natl. Acad. Sci. U.S.A., 1995; 92: 6200-6204.

42. Newbert R.W., Barton B., Greaves P., Harper J., Turner G. Analysis of a commercially improved Penicilliumchrysogenum strain series: involvement of recombinogenic regions in amplification and deletion of the penicillin biosynthesis gene cluster. J. Ind. Microbiol. Biotechnol., 1997; 19: 18-27.

43. Fierro F., Garcna-Estrada C., Castillo N.I., Rodrnguez R., Velasco-Conde T., Marton J.F. Transcriptional and bioinformatic analysis of the $56.8 \mathrm{~kb}$ DNA region amplified in tandem repeats containing the penicillin gene cluster in Penicillium-chrysogenum. Fungal Genet. Biol., 2006; 43: 618-629. 